\title{
NEPHROPROTECTIVE ACTIVITY OF PLUMERIA RUBRA AGAINST CISPLATIN INDUCED NEPH ROTOXICITY IN EXPERIMENTAL RATS
}

\author{
A. V. YADAVa, C. D. UPASANI ${ }^{a}$ \\ aDepartment of Pharmacology, SNJB's Shriman Sureshdada Jain College of Pharmacy, Chandwad, India \\ Email: yadavamruta4@gmail.com
}

Received: 19 Dec 2018 Revised and Accepted: 06 Mar 2019

\begin{abstract}
Objective: The current study was designed to evaluate the protective effect of standardized hydroalcoholic extract of Plumeria rubra (HAEPR) against cisplatin-induced nephrotoxicity in Wistar rats.

Methods: HAEPR was administered orally at 3 dose levels $(100,200,400 \mathrm{mg} / \mathrm{kg})$. Vitamin E $(250 \mathrm{mg} / \mathrm{kg})$ was used as a Standard nephroprotective agent. The kidney function test (estimation of serum creatinine, albumin, blood urea nitrogen) oxidative stress study (estimation of superoxide dismutase, malondialdehyde activity) and histological examination of kidneys was conducted.

Results: The efficacy of HAEPR was compared with Cisplatin (CP) treated group. Serum creatinine and BUN was significantly ( $\mathrm{p}<0.01)$ elevated in CP-treated group compared to the control group. HAEPR $(100,200 \mathrm{mg} / \mathrm{kg})$ and Vitamin E $(250 \mathrm{mg} / \mathrm{kg})$ significantly $(\mathrm{p}<0.01)$ decreased the serum creatinine and BUN levels. CP treated group exhibited significant $(\mathrm{p}<0.01)$ decrease in albumin when compared to control. Significant $(\mathrm{p}<0.01)$ increase in the serum albumin level was found in HAEPR $(100,200 \mathrm{mg} / \mathrm{kg})$ and Vitamin E $(250 \mathrm{mg} / \mathrm{kg})$ compared to CP group. Significant (p<0.01) decrease in the activity of SOD was observed in the CP group as compared to control. HAEPR (100 and $200 \mathrm{mg} / \mathrm{kg})$ and Vitamin E (250 mg/kg) significantly $(\mathrm{p}<0.01)$ increased SOD levels. HAEPR $(400 \mathrm{mg} / \mathrm{kg})$ significantly $(\mathrm{p}<0.05)$ increased SOD levels. HAEPR $(100,200,400 \mathrm{mg} / \mathrm{kg})$ significantly $(\mathrm{p}<0.01)$ decreased MDA levels as compared to CP group. Histopathological examination of the kidneys showed that HAEPR markedly ameliorated Cisplatin-induced renal tubular necrosis. An extract was found effective at all doses, although low dose (100 mg/kg) was found to be more effective and comparable with the standard group (Vitamin E $250 \mathrm{mg} / \mathrm{kg}$ ).
\end{abstract}

Conclusion: Present investigation revealed that HAEPR resulted in attenuation of Cisplatin-induced renal damage in rats.

Keywords: Plumeria rubra, Cisplatin, Nephrotoxicity, Creatinine, Oxidative stress

(C) 2019 The Authors. Published by Innovare Academic Sciences Pvt Ltd. This is an open access article under the CC BY license (http://creativecommons.org/licenses/by/4.0/) DOI: http://dx.doi.org/10.22159/ijpps.2019v11i4.31561

\section{INTRODUCTION}

The urinary tract is the body's drainage system of excretion of urine that is composed of wastes and extra fluid. It causes the elimination of nitrogenous waste produced by protein digestion from the bloodstream. The urinary system posseses the ability to distinguish between useful and toxic compounds in the blood that should be maintained or eliminated. Kidneys play an important role in maintaining normal blood $\mathrm{pH}$ by eliminating and maintaining acidic and basic compounds in the blood. The functional units called nephrons are capable of distinguishing between the different compounds dissolved in the blood, and eliminating only those that are not beneficial [1]. Numerous conditions like Diabetes, hypertension, Glomerulonephritis autoimmune disease result in damage to the kidneys, thus affecting their ability to filter waste from the blood [2]. Cisplatin exerts dose dependant nephrotoxicity which limits its clinical usage in cancer chemotherapy. It induces apoptosis and necrosis of renal tubular cells by activation of extrinsic and intrinsic mitochondrial pathways. It also involves p53 mediated proapoptic activation of proinflammatory pathways. Proinflammatory pathways activation and infiltration of inflammatory cells are major mechanisms in cisplatin-induced nephrotoxicity [3]. The kidney accumulates cisplatin to a greater extent unlike other organs and is the major route for its excretion. The cisplatin concentration in proximal tubular epithelial cells is about 5 times the serum concentration [4]. The disproportionate accumulation of cisplatin in kidney tissue contributes to cisplatin-induced nephrotoxicity [5]. Cisplatin is a strong cellular toxin and nephrotoxicity is one of the most important complications of this drug in clinical and experimental models. The highest concentration of cisplatin is observed in mitochondria, nuclaei, cytosol and microsomes. Nephrotoxicity induced by CP is mediated by mitogen-activated protein kinase (MAPK) intracellular signaling pathways. The MAPK pathways are activated by diverse extracellular physical and chemical stresses that regulate cell proliferation, differentiation, and survival [6]. Primary targets of cisplatin in the kidney are the proximal and distal convoluted tubules where it accumulates and promotes cellular damage, by multiple mechanisms including oxidative stress, DNA damage and apoptosis [6]. Cisplatin is interlaced to glutathione and metabolized through a gamma-glutamyl transpeptidase and cysteine S-conjugate $\beta$-lyase-dependent pathways to a reactive thiol. The kidney accumulates cisplatin by peritubular uptake and concentration of the drug in the renal cortex is several folds greater than other organs [7]. Platinum compounds mediate their cytotoxic effects by interaction with DNA. In an aqueous environment, the chloride ligands of cisplatin are replaced by water molecules generating a positively charged electrophile. The electrophile reacts with nucleophilic sites on intracellular macromolecules to form DNA, RNA, and protein adducts. Cisplatin binds to DNA leading to the formation of inter and intrastrand crosslinks, thereby arresting DNA synthesis and replication in rapidly proliferating cells $[8,9]$.

A large number of medicinal plants are claimed to be useful in renal failure in all traditional systems of medicine and folklore. Plumeria rubra trees are found throughout in India and in tropical areas. Though the plant and its extracts have been extensively used in the folklore medicines, information from an organized search of published literature does not provide the evidence for its nephroprotective activities. In the present study, we have investigated the nephroprotective activity of hydroalcoholic extract of the flowers of Plumeria rubra in Wistar rats. Plumeria species have been reported to have antimicrobial $[10,11]$ anticancer [12-14] antidiabetic activities [15, 16]. It has been identified as having potential antioxidant property. The antioxidant capacities of plant extracts are due to their radical scavenging activity, binding of transition metal ion catalysts, increasing endogenous status of antioxidant enzymes to prevent oxidative damage [17]. 


\section{MATERIALS AND METHODS}

\section{Chemicals}

Standardized hydroalcoholic extract of Plumeria rubra (HAEPR) was pro cured from Shamantak enterprises, Pune. Cisplatin cis-diamineplatinum (II) dichloride was purchased from S. K. Enterprises, Pune. All other chemicals used were of the analytical grade.

\section{Animals}

Thirty-six Wistar male and female albino rats, weighing 200-250g, were used for the study. The animals were maintained under standard laboratory conditions with controlled temperature $\left(20 \pm 2{ }^{\circ} \mathrm{C}\right)$ and humidity (60\%) with regular light cycle (12 light/12 dark). The animals were acclimatized for $1 \mathrm{w}$ before the study and had free access to standard laboratory food and water ad libitum. All experimental procedures were conducted in accordance with the principles for the care and use of laboratory animals in research and approved by the institutional animal ethics committee. (ACP/IAEC/2018/01).

\section{Experimental design}

The nephroprotective activity was tested on six groups of albino Wistar rats (3 males +3 females) each group consisting of six animals.

Group I-Served as control received normal saline (0.9\%; p. o)

Group II-Toxic control rats received normal saline (0.9\%; p. o) and cisplatin $(6 \mathrm{mg} / \mathrm{kg}$; i. p)

Group III-Received Vitamin E $250 \mathrm{mg} / \mathrm{kg}$ as Standard nephroprotective agent and cisplatin $(6 \mathrm{mg} / \mathrm{kg}$; i. p)

Group IV-Received HAEPR (100 mg/kg; p. o) and cisplatin (6 mg/kg; i. p) Group V-Received HAEPR (200 mg/kg; p. o) and cisplatin (6 mg/kg; i. p) Group VI-Received HAEPR (400 mg/kg; p. o) and cisplatin (6 mg/kg; i. p)

On the 15th day, $2 \mathrm{~h}$ after the administration of extracts and normal saline groups II-VI received CP $(6 \mathrm{mg} / \mathrm{kg} ;$ i. p). At the end of the experimental period, i. e on the 16th-day rats were sacrificed by cervical dislocation. The blood was collected in an anticoagulant tube and allowed to stand for $30 \mathrm{~min}$ at $37^{\circ} \mathrm{C}$ and then centrifuged to separate the serum to evaluate the biochemical markers [18-20]. Serum MDA was measured using the method of Buege. In this method, $100 \mu \mathrm{L}$ serum was diluted to $500 \mu \mathrm{L}$ distilled water. The samples were kept in a boiling water bath for $15 \mathrm{~min}$. To the diluted sample $1 \mathrm{ml}$ of Trichloroacetic acid TCA-2-thiobarbituric acid (TBA) $\mathrm{HCl}$ reagent was added. The reaction mixture was cooled and centrifuged. The supernatant was taken and the optical density of the pink color formed was read at $535 \mathrm{~nm}$. The optical density of the pink color formed was directly proportional to the concentration of serum MDA in the given sample [21]. Serum superoxide dismutase activity was estimated by Marklund and Marklund method. In this method superoxide anion is involved in auto-oxidation of pyrogallol at alkaline $\mathrm{pH}$ (8.5). The superoxide dismutase (SOD) inhibits autooxidation of pyrogallol. This can be determined as an increase in absorbance at $420 \mathrm{~nm}$. [22]. Jaffe's Alkaline picrate method was used for creatinine estimation. Creatinine reacts with alkaline picrate to give orange color. Intensity of the color formed was directly proportional to the amount of creatinine present in the sample. Albumin determination was done by the Biuret method. Albumin present in globulin, free solution react with copper sulphate in an alkaline medium to give violet color [23]. The blood urea nitrogen was estimated by the Berthelot method. Urease catalyses the conversion of urea to ammonia and carbon dioxide. The ammonia, thus released reacts with a mixture of salicylate, hypochlorite and nitroprusside to yield indophenol, a blue-green colored compound. The intensity of the color produced is directly proportional to the concentration of urea in the sample and was measured spectrophotometrically at $578 \mathrm{~nm}$ [24].

\section{Histopathology}

Fixation of the kidney was done by cutting and fixing in Bouin's fluid immediately after removal from the animal body. The tissues were fixed in Bouin's fluid for about $24 \mathrm{~h}$. The tissues were then taken and washed in glass distilled water for a day to remove excess of picric acid. This was followed by Dehydration in which the tissues were kept in the following solutions for an hour each; 30\%, 50\%, 70\% and $100 \%$ alcohol. Xylene was used as the clearing agent, for one or two hours, two or three times. The tissues were taken out of xylene and were kept in molten paraffin embedding bath with molten wax maintained at about $50{ }^{\circ} \mathrm{C}$. A clear glass plate was smeared with glycerine. L-shaped mould was placed on it to from a rectangular cavity. The molten paraffin wax was poured and air bubbles were removed by using a hot needle. The tissue was placed in the paraffin and oriented with the surface to be sectioned. Then the tissue was pressed gently towards the glass plate to make settle uniformly with a metal pressing rod and allowed the wax to settle and solidity room temperature. The paraffin block was kept in cold water for cooling. Section cutting was done with a rotatory microtome. The excess of paraffin around the tissue was removed by trimming, leaving $1 / 2 \mathrm{~cm}$ around the tissue. Then the block was attached to the gently heated holder. To produce uniform sections, the microtome knife was adjusted to the proper angle in the knife holder with only the cutting edge coming in contact with the paraffin block. The tissue was cut in the thickness range of about $7 \mu \mathrm{m}$. The sections were spread on a warm water bath after they were detached from the knife with the help of hair brush. Required sections were spread on a clean slide and kept at room temperature. The sections were stained as follows; deparaffinization with xylene two times each for five minutes. Dehydration through descending grades of ethyl alcohol. Staining with Ehrlich's Haemaoxylin was done for 15-

$20 \mathrm{~min}$. Then the sectioned tissues were thoroughly washed in tap water for $10 \mathrm{~min}$. Rinsed with distilled water and stained with Eosin. Dehydration again with ascending grades of alcohol. Finally, the tissues were cleared with xylene two times, each for about $3 \mathrm{~min}$ interval. On the stained slide, DPX mountant was applied uniformly and micro glass cover slides were spread. The slides were observed in Nikon microscope and microphotographs were taken [25].

\section{Statistical analysis}

The results were expressed as mean \pm SEM. Comparison between the groups was made by one-way analysis of variance (ANOVA) followed by "Dunnett's Test". $\mathrm{P}<0.05$ was considered to be significant.

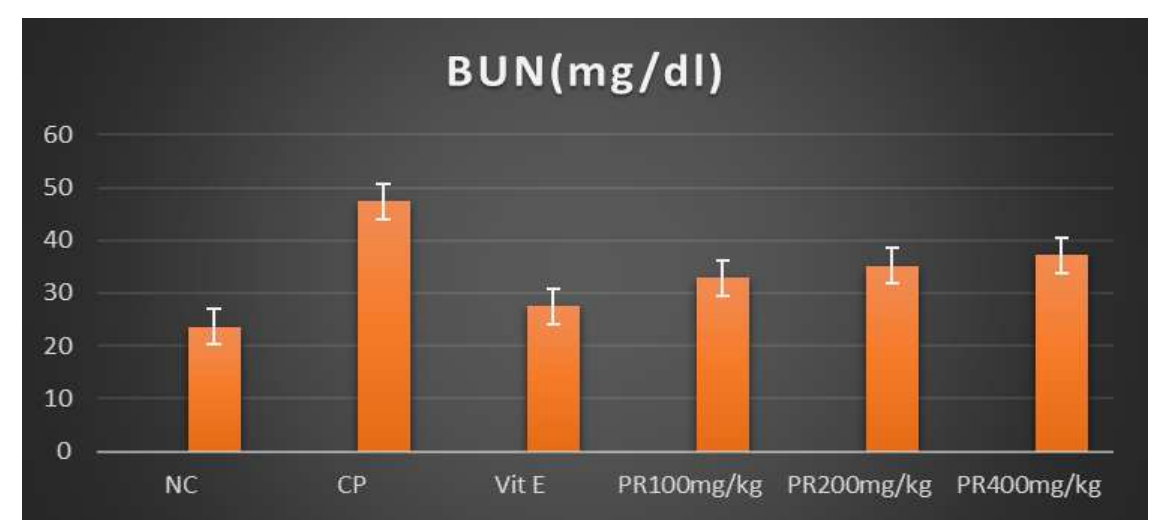

Fig. 1: Effect of HAEPR on BUN 


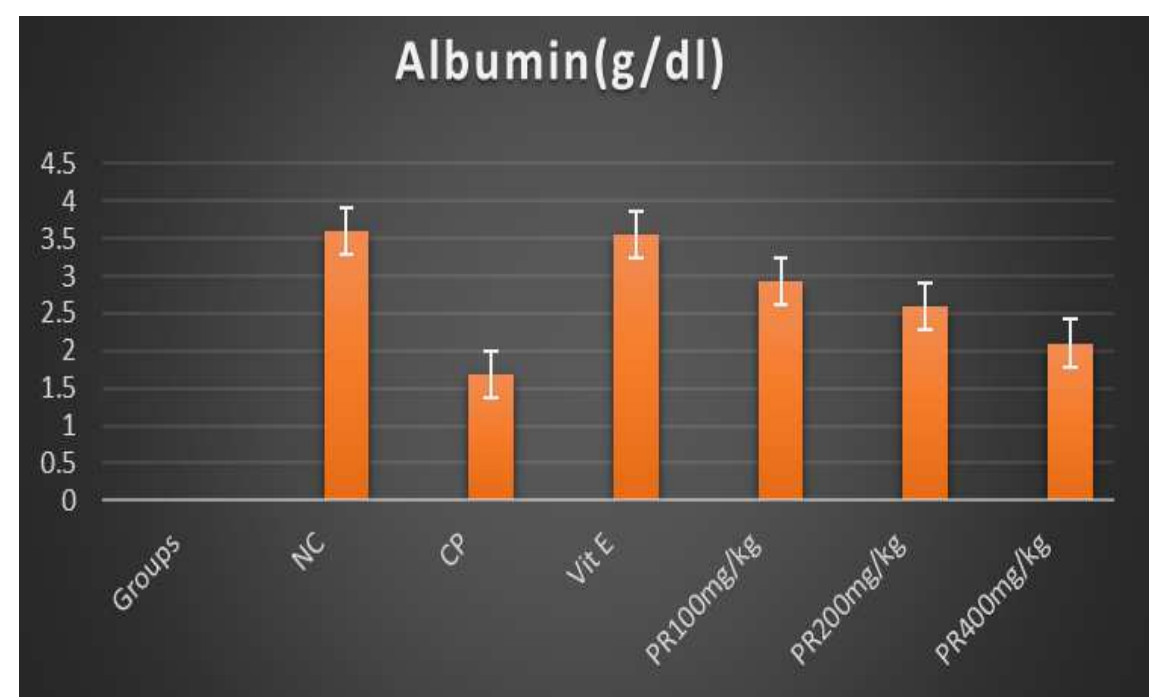

Fig. 2: Effect of HAEPR on Albumin

\section{Creatinine $(\mathrm{mg} / \mathrm{dl})$}

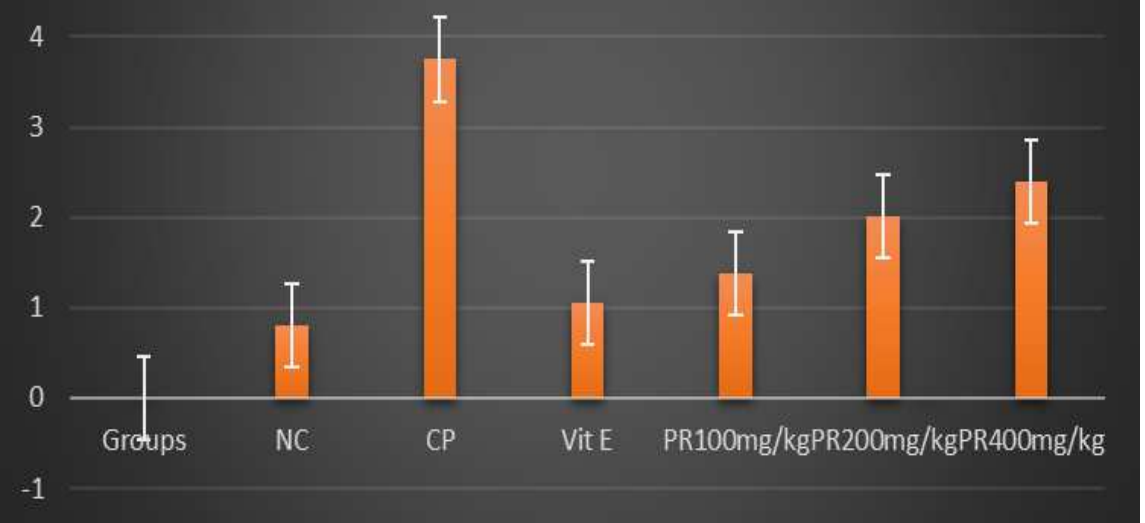

Fig. 3: Effect of HAEPR on creatinine

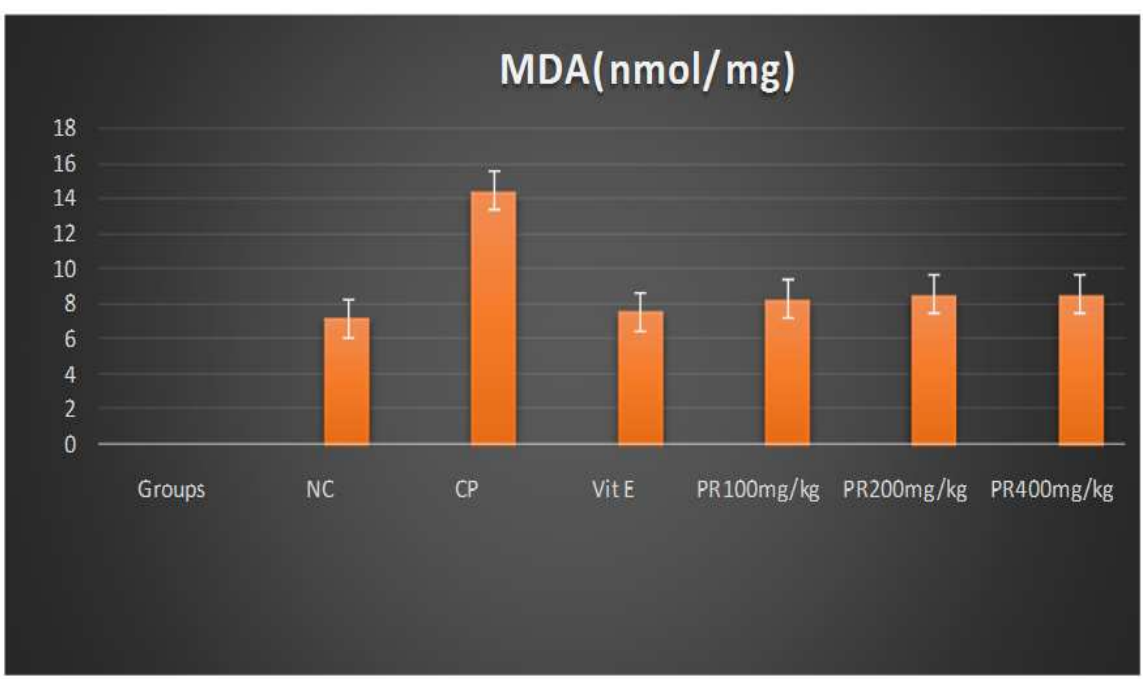

Fig. 4: Effect of HAEPR on MDA 


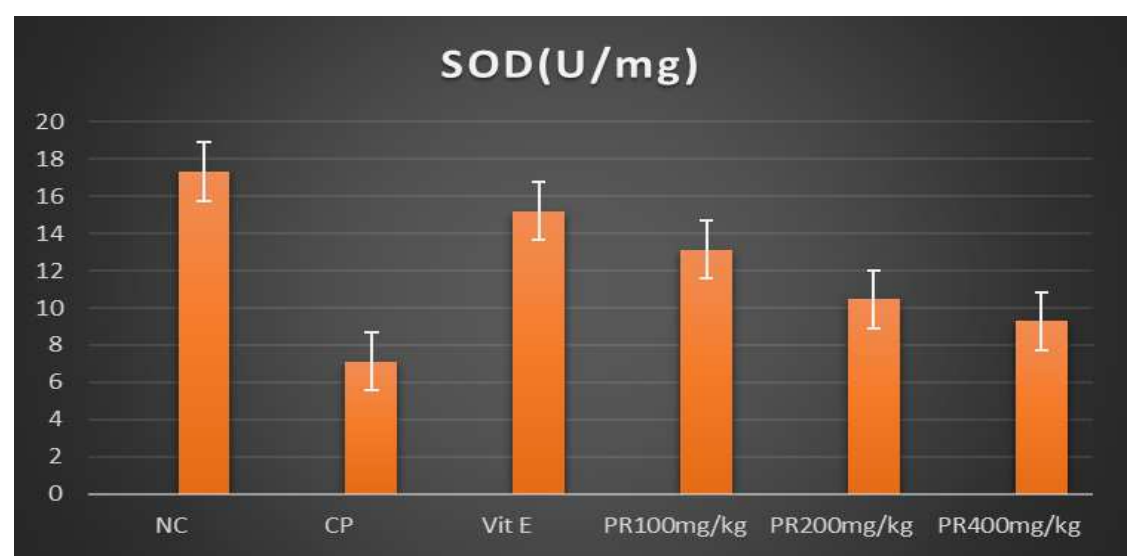

Fig. 4: Effect of HAEPR on SOD

\section{RESULTS}

\section{Biochemical analysis}

Serum creatinine was significantly $(\mathrm{p}<0.001)$ elevated in the $C P$ group when compared to control group. HAEPR treatment $(100,200$ $\mathrm{mg} / \mathrm{kg})$ and Vitamin E $(250 \mathrm{mg} / \mathrm{kg})$ significantly $(\mathrm{p}<0.01)$ decreased the serum creatinine levels as compared to the CP group. CP group exhibited significant $(p<0.001)$ decrease in albumin when compared to control. Significant $(\mathrm{p}<0.01)$ increase in the serum albumin level was found when compared to the CP group by HAEPR $(100,200$ $\mathrm{mg} / \mathrm{kg})$ and Vitamin E $(250 \mathrm{mg} / \mathrm{kg})$ treatment. Serum BUN level was significantly $(\mathrm{p}<0.001)$ elevated in the CP group compared with control group. HAEPR $(100,200 \mathrm{mg} / \mathrm{kg})$ significantly $(\mathrm{p}<0.01)$ decreased the serum BUN level as compared with the CP control group. HAEPR ( $100 \mathrm{mg} / \mathrm{kg}$ ) was comparable to that of the standard group. Significant $(p<0.001)$ decrease in the activity of SOD was observed in the CP group as compared to control. HAEPR (100 and $200 \mathrm{mg} / \mathrm{kg})$ significantly $(\mathrm{p}<0.01)$ increased SOD level when compared to the CP group. HAEPR $(400 \mathrm{mg} / \mathrm{kg})$ significantly $(p<0.05)$ increased SOD levels. Significant $(p<0.001)$ increase in the activity of MDA was observed in the CP group as compared to control. HAEPR $\quad(100,200,400 \quad \mathrm{mg} / \mathrm{kg}) \quad$ significantly $(\mathrm{p}<0.01)$ decreased MDA levels as compared to the CP group. HAEPR (100 $\mathrm{mg} / \mathrm{kg}$ ) exhibited results similar to that of std Vitamin E.

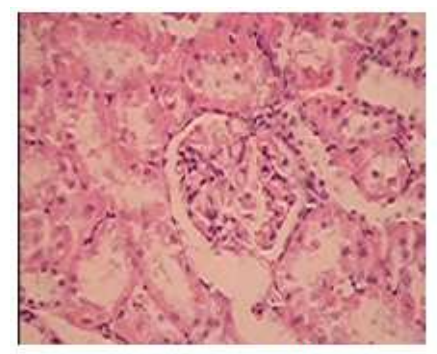

Normal Control

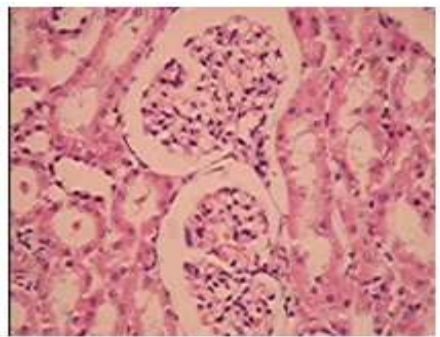

Vitamin $1250 \mathrm{mg} / \mathrm{kg}$

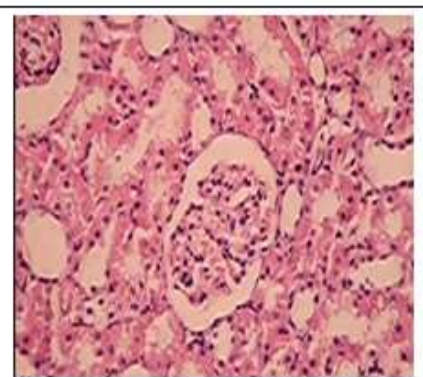

HAEPR $200 \mathrm{mg} / \mathrm{kg}$

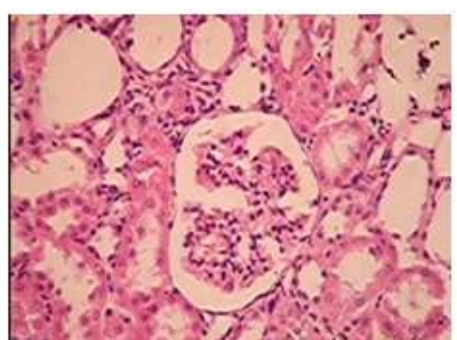

CP

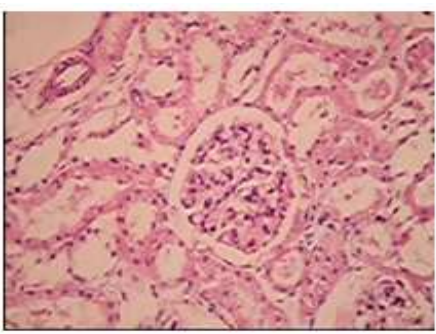

HAEPR $100 \mathrm{mg} / \mathrm{kg}$

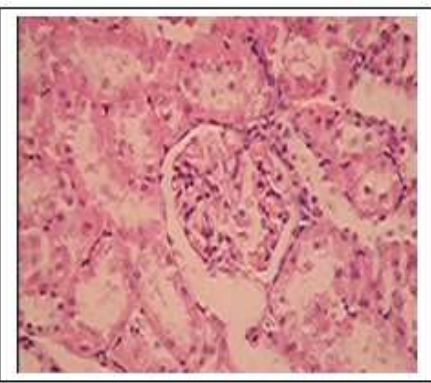

HAEPR $400 \mathrm{mg} / \mathrm{kg}$

Fig. 6: Effect of HAEAR on histopathology of kidneys 


\section{DISCUSSION}

Cisplatin is an effective compound in the treatment of several cancers. Its clinical use, however, is associated with severe adverse effects. Main side effect that limits the usage in treatment of cancer is nephrotoxicity. Cisplatin in the kidneys penetrates the tubular cells and reaches high concentration in the proximal tubules Glomerular injury is less frequent. Tubular damage manifests through impaired reabsorption that is characterized by reduced glomerular filtration rate, increased serum creatinine and blood urea concentrations. The pathophysiological mechanism of cisplatin-induced tubular damage involves a number of interconnected factors like accumulation of cisplatin and conversion into nephrotoxins, DNA damage, mitochondrial dysfunction oxidative stress, inflammatory response, activation of signal transducers and intracellular messengers and activation of apoptotic pathways [26]. The kidney accumulates and retains platinum to a greater degree than other organs and is the principal excretory organ for injected cisplatin. In the rat, the kidney excretes the drug rapidly within the first hour of its administration by a process consisting predominantly of glomerular filtration, with a minor component of secretion. There is no evidence of tubular reabsorption, suggesting that the kidney accumulates cisplatin by peritubular uptake. The uptake of cisplatin by the kidney is dependent on temperature and the normal consumption of oxygen and can be inhibited by drugs that participate in the organic base transport system, suggesting that at least some portion of renal cisplatin uptake is facilitated. Cisplatin predictably lowers glomerular filtration rate in a dose-dependent manner, even after single drug exposure. The onset of renal failure is gradual, usually occurring 3 to $5 \mathrm{~d}$ after its administration. Early proteinuria is mild (500 mg/d), as is glycosuria. Enzymuria is common,even in the mildest forms of acute renal failure [5]. The present investigation aims to evaluate the protective effect of HAEPR against cisplatininduced nephrotoxicity and degree of functional alterations in the kidneys by histopathological and biochemical analysis. Cisplatin (6 $\mathrm{mg} / \mathrm{kg}$ ) was used to induce nephrotoxicity. Vitamin E was one of the antioxidant standard used to ameliorate cisplatin-induced nephrotoxicity in rats. Creatinine is the by-product of muscle metabolism. It is transported from the bloodstream to the kidneys. The kidneys filter most of the creatinine and maintain the normal range of creatinine. Impairment in the kidney function rises creatinine level in the blood causing poor clearance of creatinine. Abnormally high levels of creatinine thus warn of a possible malfunction of the kidneys. Blood urea nitrogen (BUN) is another indicator of kidney function. Urea is also a metabolic byproduct that is elevated if kidney function is impaired [27]. BUN level rises if kidney function decreases. Hypoalbuminaemia is the strongest predictor of death in patients with renal failure. Patients with lower serum albumin level have consistently higher morbidity rates [28]. Reduction in the GFR was indicated by increased levels of creatinine and BUN [29]. A significant decrease in serum albumin also indicated renal impairment. Treatment with the HAEPR at the dose level of 100, 200 and 400 $\mathrm{mg} / \mathrm{kg}$ body weight significantly lowered the level of creatinine, BUN when compared with the Cisplatin (CP) treated group. It also augmented the reduced levels of albumin. SOD is the primary line of defense against free radical-induced oxidative stress. It causes catalytic dismutation of highly reactive and potentially toxic superoxide radical to hydrogen peroxide [30]. Plants have evolved various protective mechanisms for minimising deleterious effects of free radicals. The enzymatic defence comprises of the efficient antioxidant enzymes such as catalase, peroxidase, superoxide dismutase [31].

Increased ROS production in renal tissue is responsible for damage of organs marked by changes in levels of MDA and SOD. MDA levels were significantly increased in rats treated with $\mathrm{CP}$ when compared to control group. HAEPR significantly attenuated the MDA levels in renal tissue probably due to its capacity to scavenge oxygen free radicals in the kidneys. Moreover, it also significantly increased the levels of SOD resulting in improvement of kidney function and histopathology. Impairment in the histological features of the kidneys was substantiated by CP treatment. Our study demonstrated histological changes in proximal and distal convoluted tubules, which were signs of tubular necrosis and atrophy of the vascular component in glomerulus in CP group. Vitamin E treated rat kidney sections showed architecture similar to normal tubules. Recovery of renal function was observed by treatment of HAEPR evidenced by the regenerative capability of the renal tubules. The experimental results reveal that the nephroprotective activity of the extract is comparable to that of Vitamin E. The activity elicited by the extract might be due to its ability to activate antioxidant enzymes.

\section{CONCLUSION}

The study concludes that cisplatin injury evidenced elevated biochemical markers and histopathological features of acute tubular necrosis. The administration of HAEPR resulted in attenuation of $\mathrm{CP}$ induced renal damage. The nephroprotective potential may be due to its antioxidant properties. Further studies are required to characterize the phytoconstituents from HAEPR and to study the exact mechanism of action.

\section{AUTHORS CONTRIBUTIONS}

Both the authors contributed equally in preparing, editing, and reviewing the article.

\section{CONFLICTS OF INTERESTS}

\section{All authors have none to declare}

\section{REFERENCES}

1. Kirstin Hendrickson, Why is the Urinary System Important? Livestrong.com.

Available from: http://www.livestrong.com/article/200414why-is-the-urinary-system-important. [Last accessed on 28 Nov 2018]

2. Kidney Disease. labtestsonline.org. Available from: https://labt estsonline.org/understanding/conditions/kidney/start. [Last accessed on 20 Oct 2018]

3. Sahu BD, Kalvala AK, Koneru M, Jerald MK, Kuncha MS, Rachamalla SS, et al. Ameliorative effect of fisetin on cisplatin induced nephrotoxicity in rats via modulation of NF-kB activation and antioxidant defence. Plos One 2014;9:1-15.

4. Kuhlmann MK, Burkhardt G, Kohler H. Insights into potential cellular mechanisms of cisplatin nephrotoxicity and their clinical application. Nephrol Dial Transplant 1997;12:2478-80.

5. Arany I, Safirstein RL. Cisplatin nephrotoxicity. Semin Nephrol 2003;23:460-4.

6. Chatterjee P, Mukherjee A, Nandy S. Protective effects of the aqueous leaf extract of aloe barbadensis on gentamicin and cisplatin-induced nephrotoxic rats. Asian Pac J Trop Biomed 2012;2:S1754-S1763.

7. Hayati F, Hossainzadeh M, Shayanpour S, Gheshlaghi ZA, Mousavi SS. Prevention of cisplatin nephrotoxicity. J Nephropharmacol 2016;5:57-60.

8. Miller RP, Tadagavadi RK, Ramesh G, Reeves WB. Mechanisms of cisplatin nephrotoxicity. Toxins 2010;2:2490-518.

9. Yao X, Panichpisal K, Kurtzman N, Nugent K. Cisplatin nephrotoxicity: a review. Am J Med Sci 2007;334:115-4.

10. Sibi G, Awasthi S, Dhananjaya K, Mallesha H, Ravikumar KR. Comparative studies of Plumeria species for their phytochemical and antifungal properties against citrus sinensis pathogens. Int J Agric Res 2012;7:324-31.

11. Rasool SN, Jaheerunnisa S, Chitta SK, Jayaveera KN. Antimicrobial activities of Plumeria acutifolia. J Med Plants Res 2008;2:77-80.

12. Ramalingam R, Sivakumar T. In-vitro and in-vivo anticancer activity of leaves of plumeria alba Linn. J Pharm Res 2009; 2:203-7.

13. Radha R, Kavimani S, Ravichandran V. Antitumour activity of methanolic extract of plumeria alba L. leaves against dalton lymphoma ascites in mice. Int J Health Res 2008;1:79-85.

14. Rekha JB, Jayakar B. Anticancer activity of ethanolic extract of leaves of plumeria rubra L. Curr Pharm Res 2011;1:175.

15. Yadav AV, Undale VR. Antidiabetic activity of plumeria rubra L. in normal and alloxan-induced diabetic mice. Int J Basic Clin Pharmacol 2016;5:884-9.

16. Yadav AV, Undale VR. Antidiabetic effect of plumeria rubra L. in streptozotocin-induced diabetic rats. Int JPharm Sci Res 2017;8:1806-12.

17. Merina AJ, Sivanesan D, Begum VH, Sulochana N. Antioxidant and hypolipidemic effect of Plumeria rubra L. in alloxan induced hyperglycemic rats. J Chem 2010;7:1-5. 
18. Yousef MI, Saad AA, El Shennawy LK. Protective effect of grape seed proanthocyanidin extract against oxidative stress induced by cisplatin in rats. Food Chem Toxicol 2009;47:1176-83.

19. Debnath S, Babre N, Manjunath YS, Mallareddy V, Parameshwar P, Hariprasath K. Nephroprotective evaluation of ethanolic extract of the seeds of papaya and pumpkin fruit in cisplatininduced nephrotoxicity. J Pharm Sci Tech 2010;2:241-6.

20. Yadav AV, Upasani CD. Nephroprotective activity of asparagus $r$ acemosus against cisplatin-induced nephrotoxicity and renal dysfunction in experimental rats. Asian J Pharm Clin Res 2018;11:230-3.

21. Buege JA, Aust SD. Microsomal lipid peroxidation. Methods Enzymol 1978;52:302.

22. Marklund S, Marklund G. Involvement of the superoxide anion radical in the autoxidation of pyrogallol and a convenient assay for superoxide dismutase. Eur J Biochem 1974;47:469-74.

23. Rajagopal G, Toora BD. Practical biochemistry. 2nd edition. Ahuja publishing house; 2005. p. 98-112.

24. Fawcett JK, Scott JE. A rapid and precise method for the determ ination of urea. J Clin Pathol 1960;13:156-9.
25. Bancroft D, Stevens A, Turner R. Theory and practice of histolog ical technique. $4^{\text {th }}$ edition. Churchill Livingstone, Edinburgh, London, Melbourne; 1996. p. 53-83.

26. Ilic S, Stojiljkovic N, Veljkovic M, Veljkovic S, Stojanovic G. Protectiv e effect of quercetin on cisplatin-induced nephrotoxicity in rats. Facta Universitatis, Series: Med Biol 2014;16:71-5.

27. Viswanathan V, Snehalatha C, Kumutha R, Jayaraman M, Ramac handran A. Serum albumin levels in different stages of type 2 diabetic nephropathy patients. Indian J Nephrol 2004;14:89-92.

28. Balakumar P, Chakkarwar VA, Kumar V, Jain A, Reddy J, Singh M. Experimental models for nephropathy. J Renin Angiotensin Aldosterone Syst 2008;9:189-95.

29. Domitrovic R, Potocnjak I, Orlic ZC, Skoda. Nephroprotective ac tivities of rosmarinic acid against cisplatin-induced kidney injury in mice. Food Chem Toxicol 2014;66:321-8.

30. Gautam RK, Singh RK, MS Karchuli. Evaluation of nephroprotective activity of mentha arvensis in cisplatininduced nephrotoxicity. Asian J Pharm Clin Res 2014;7:188-91.

31. Gupta SK, Najnin I, Choudhuri C, Mandal P. Elicitation of therapeutic potential and oxidative stress assessment of fenugreek sprouts under UV irradiation. Int J Pharm Pharm Sci 2017;9:91-9. 